\title{
Medical Support of Airborne Operations
}

\author{
Lt Col L P Lillywhite \\ MBE, MB, Bch, psc, RAMC \\ Headquarters 23 Parachute Field Ambulance RAMC, Rhine Barracks, Aldershot, Hampshire GU112AX
}

\section{Introduction}

In 1984 the Government anneunced the enhancement of 5 Airborne Brigade (5 AB Bde) for operations outside the NATO area (Out of Area or OOA operations) $^{1}$. These enhancements included the addition of a medical unit (a field ambulance formed from the expansion of the existing Parachute Clearing Troop) whose lack had been seen as one of the logistic deficiencies during the Falkland Islands campaign ${ }^{2}$. This paper describes the medical support provided by the reformed field ambulance. It also considers the influence of human factors in OOA and Airborne operations and the Brigade policy to minimise these effects.

\section{Airborne Operations}

In order to put medical support into context it is first necessary to consider the nature of Airborne Operations. These include both Parachute operations, where a force is delivered by parachute (such as the rescue of European civilians by French and Belgian troops in Kolwesi in 1978), and tactical airland assault operations, where the aircraft disembark the assaulting troops onto a hostile airfield after landing (such as the rescue of the hijacked passengers at Entebbe by Israeli troops in 1976). Whichever operation is involved there are limitations which affect logistic, including medical, support.

Aircraft are always limited in numbers and Airborne Forces have to be lightly equipped. For some time after landing the force has to be completely self-contained without reinforcements and with no open lines of communication. The force may be outnumbered by an enemy who will also be more heavily armed and will know the ground. The delivery of an airborne force rarely goes according to plan and some aircraft will not arrive, others will not discharge all their personnel or equipment, whilst some will drop their loads wide of the dropping zone.

Human factors are significant. The flight is usually long, mostly at low level and results in a rough journey (inducing motion sickness) which will end at an objective in an unknown, and possibly hot, country. The uncertainty of re-supply leads to troops having to carry up to $120 \mathrm{lbs}$ of equipment each. Furthermore, for up to 40 minutes prior to a parachute assault, troops have to stand with this equipment whilst wearing another 61lbs of parachute equipment (a total of one and a half hundredweight). Once on the ground, individual initiative will be required by all ranks as they reform into units. Finally, there is the knowledge that they are isolated and may be facing an enemy superior in numbers and equipment.

Preparation for such operations must therefore start $\frac{\sigma}{\bar{c}}$. with selection of personnel. All parachute personnel $\overrightarrow{\mathbb{\nabla}}$

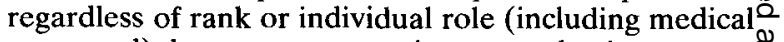
personnel) have to pass a rigorous selection course which tests physical and mental endurance, the ability to $\vec{\circ}$ integrate as a team and, in the case of officers and seniornon-commissioned officers (NCOs), leadership.

\section{Medical Support}

Many personnel in $5 \mathrm{AB}$ Bde have been on active? service; others will have seen, or been, one of the $\vec{w}$ casualties that regularly occur during parachute training (approximately 0.7 casualties per 100 descents).N Medicine and medical training is thus seen by most commanders and soldiers to be important and relevant.을 The field ambulance Commanding Officer is BrigadeSenior Medical Officer with an office in Brigade HQ a $\overrightarrow{p d} \mathrm{C}$ he reports direct to the Brigade Commander on $\$ 115$ medical matters. Along with three other Brigade staff officers (Chief of Staff, Deputy Chief of Staff and the Staff Officer for Air Matters) he is involved from the. earliest stages in operational and exercise planning. This policy is intended to ensure that medical factors whioh might affect the outcome of an operation are taken into consideration during initial planning. It also ensures that any additional medical resources required are obtained,,$\stackrel{\mathbb{Q}}{\mathscr{Q}}$ and that the medical plan is compatible with the operational task of the Brigade.

For the non-medical units of the Brigade, medical preparation involves the areas of Army Health - Firsto Aid training and the efficiency of Regimental Aid Posts. Proficiency is tested on exercise and on each unit's annual medical supporting inspection. On the latter individual officers and soldiers are selected at randoms and tested in basic practical skills. Unit specialists, eg, $\mathbb{D}$ water duties personnel and medical assistants, are $\bar{F}$ similarly tested. In addition to the basic first aid requiredo of all ranks in the British Army, all units are required to have advanced first aiders who have been taught on aô three week unit course, usually with a subsequent $₹$ hospital attachment, on the scale of one per section. Ino fact, most units have more than their required numbers, $\rightarrow$ while others have set (though not yet achieved) a higher을. target such as one per vehicle crew. There are two annual competitions into which all sub-units of company size or equivalent have to enter a ten man team. One is a ${ }^{\circ}$ stretcher bearer competition, the other, for all units having a Regimental Aid Post (RAP), is a RAPO 
competition. In addition to testing the normal RAP skills, this latter competition also tests the RAP's ability to function without a vehicle. Both competitions combine military and medical skills. Casualty evacuation is regularly practiced on exercise with full support from Commanding Officers whose only complaint has been that too few casualties have sometimes been allocated. In order to minimise the effects of heat on unacclimatised troops much emphasis is placed on fitness training as fitness is claimed to reduce the time required for full acclimatisation. Standard operating procedures also require the use of prehydration and levels of activity which are related to the Wet-Dry Bulb Globe Index.

\section{The Parachute Field Ambulance}

5 AB Bde is supported by a small field ambulance of 131 Personnel, 23 Parachute Field Ambulance (23 PFA). The term "field ambulance" is, however, misleading. The function of a field ambulance is the collection of casualties, their subsequent sustenance and their preparation for evacuation to hospital. This would be inadequate for $5 \mathrm{AB}$ Bde because lines of evacuation are unlikely to be open in the early stages of an operation, and tenuous later, and there is unlikely to be any hospital to which to evacuate. Like all previous airborne and parachute field ambulances, therefore, the major characteristic of 23 PFA is the presence of surgical teams to provide life saving surgery. In addition to these, the unit contains a number of other sub-units, as shown in Table 1.

With the exception of the surgical teams these other sub-units are found in conventional field ambulances. The Headquarters provides overall command and control, planning for the unit, and medical planning for the Brigade, including the control of casualty evacuation from Brigade units. The Clearing Troop is responsible for the reception of casualties, the full care of minor injured, and the resuscitation and pre- and postoperative care (including ward care) of the severely injured who require surgery. The troop also includes a dental officer and a dental clerk assistant who provide dental care when not working in the resuscitation department. The Collecting Sections act as mobile medical aid posts. Two are usually deployed to reinforce battalions, and the third is held in reserve. The Hygiene Section is responsible for providing hygiene advice and assistance to Brigade units. The Ambulance Troop mans the vehicles used for land evacuation. The echelon provides logistic support to the unit and medical resupply to the unit itself and to other Brigade units.

This apparent similarity to conventional field ambulances, however, hides some major organisational differences. As the Clearing Troop has to support the surgical teams, its organisation and medical scales differ from other field ambulances. 23 PFA has a Collecting Troop of only three sections instead of the more usual Collecting Squadron with a headquarters and six or seven sections. The vehicle establishment of 23 PFA is much smaller (a total of 23 vehicles, including three ambulances and two 4-ton vehicles, compared to a wheeled field ambulance's 55, including 18 ambulances and eleven four ton vehicles), and it relies on ordinary landrovers fitted for stretcher for land evacuation. The small vehicle establishment means that there is a smaller number of non-medical/dental personnel in the unit and they account for only $27 \%$ of the other-rank strength compared to $41 \%$ to $50 \%$ in other field ambulances. Because of the need to provide and support surgery, 23 PFA has a greater range of trades including Operating Theatre Technicians, Registered General (or Enrolled General) Nurses and a Physiotherapist. It also has two of its Environmental Health Technicians in peace whereas most other field ambulances only have them in war. As a result of having these additional trades, but at the same time having far less manpower at war establishment than other field ambulances, the absolute number of Combat Medical Technicians is reduced, although as a proportion of other rank strength they still exceed by $5 \%$ those in an armoured field ambulance. It is paradoxical that although 23 PFA is the smallest field ambulance, it has the additional surgical capability. Seventy per cent of the posts are for parachutists.

\section{Table 1}

Composition of 23 Parachute Field Ambulance, RAMC

Headquarters
Surgical Teams (3)
Clearing Troop (1)
Collecting Sections (3)
Ambulance Troop
Hygiene Section
Echelon, including
$\quad$ Medical Resupply
Catering Section
Vehicle Mechanic Section

The medical materiel held by the unit is sufficien 1000 battle casualties, including 430 major surgical operations. The general stores are similar to other field ambulances except that, to enhance mobility, the tentage used is all based on the $12 \times 12$ foot modules instead of the more bulky $18 \times 24$ foot. Generators are all man-portable as are the heaters (although the ideal portable heater has not yet been discovered). The vehicle establishment is insufficient to carry all the unit equipment and some 12 pallets (mainly re-supply and spare equipment) are transported as freight. 


\section{Deployment}

Deployment is the key to ensuring successful medical support for airborne operations. The desire to put as much offensive equipment and as many fighting personnel into the aircraft lift has to be balanced against the need for those troops to deploy with their medical support. Leaving medical support behind to follow later is not considered to be an option, and the field ambulance, therefore, deploys a large element known as a Parachute Clearing Troop (PCT) with each of the first two or three battalions. This ensures that the medical build up parallels that of the fighting troops.

A PCT comprises 36-43 men including one or two surgical teams and the personnel to support those teams, drawn from the clearing troop and one of the collecting sections. In case their freight does not arrive the personnel of each surgical team carry in their rucksacks sufficient equipment for 10 to 15 operations (about one day's worth) while the other personnel carry the necessary equipment for pre- and post-operative support. Two radios are also carried for forward and rearward communications. The equipment is dispersed amongst the personnel to allow for the non-arrival of some.

When parachuting, the majority of a PCT's equipment is carried on a Medium Stress Platform (MSP) and two wedges. The MSP used is a specially designed medical variant. It has a landrover and trailer and side stores are packed around the outside. The trailer carries the surgical teams' equipment (including one $12 \times 12$ foot tent) with medical materiel sufficient for 50 major operations. The landrover and side stores are used for the Clearing Section's equipment and this includes two $12 \times 12$ foot tents and medical material to support 100 major operations and 100 minor procedures. On landing, the side stores are carried on two two-wheeled trolleys pulled behind the landrover trailer. Wedges contain approximately the same amount of equipment as a landrover trailer and are carried on the tailgate of the same aircraft as the personnel unlike the MSP's which are carried on separate aircraft. To accommodate tent poles medical wedges are bigger than normal wedges. On one is fitted a surgical team's equipment and on the other is placed either a collecting section's equipment or medical re-supply.

After landing, the personnel move to rendezvous on a marker (a flag or light), giving life-saving first aid to casualties they encounter en route. The surgical team sets up an aid post while the remainder are allocated to finding and recovering the unit freight, reconnaissance of the future location of the PCT or sweeping the DZ to find casualties and evacuate them to the aid post. This stage of an airborne operation rarely goes according to plan, and the problems associated with it will be discussed below.

In due course the PCT will come together to form a surgical centre of one or two surgical teams with the remainder providing reception, resuscitation, and pre- and post-operative care. At this stage the Collecting Section cannot be released for its conventional role as its personnel are needed to assist in the surgical centre. The $\frac{\pi}{\mathrm{d}}$ Battalion therefore has to rely solely on its Regimental $\Omega$ Aid Post if it needs medical support elsewhere. Luckilyo it is usual for the Battalion objective to be in the vicinityo of the $\mathrm{DZ}$ - for instance an airfield may be the objective and it will also be the DZ - in which case the Regimental $\underset{\overrightarrow{\vec{s}}}{\vec{\theta}}$ Aid Post may co-locate with the PCT.

The second Battalion Group to arrive will have a PCT$\frac{-}{\underline{\sigma}}$ of a similar composition to the first. On arriving it will as $\overline{\overline{\bar{s}}}$. soon as possible combine with the first to form a Brigade $\underset{\Omega}{\overparen{Q}}$ Dressing Station (DS). The two Collecting Sections (oneo deployed with each $\mathrm{PCT}$ ) can then be released to ${ }^{\infty}$ reinforce the Battalion Regimental Aid Posts if $\vec{\circ}$ required. The Commanding Officer and hygiene section $\vec{\overrightarrow{ }}$ will also arrive with the second PCT. At this stage ${ }_{\sigma}^{\omega}$ Brigade operations are probably becoming more. ambitious and pose difficulties for medical support 3 because there are only two field ambulance vehicles in? theatre. These difficulties will also be discussed below. $\vec{\omega}$ As an airfield is opened the rest of the Brigade starts $\overrightarrow{\hat{b}}$ arriving. The DS will by now probably be holding more $N$ casualties than it can reasonably manage, so priority is $\mathrm{N}$ given to deploying one or two 4-man sections of theo RAF's 1 Aeromedical Evacuation Squadron (1 A Evac$S)$. Their prime role is the preparation for and escortipg of casualties during aeromedical evacuation, but the presence also enhances post-operative care.

In due course the rest of the field ambulance will arrive and this will be followed in a major operation By. 22 Field Hospital or elements thereof. Many of problems encountered thereafter are similar to thosecक्षे a conventional field ambulance, but there are someo differences due to the unit's light scales and the presence of surgical teams.

\section{-Problem Areas}

Most of the problem areas associated witho contemporary airborne operations are the same as those encountered in Airborne Operations in World War $2^{3}$. The first problem is the planning. Airborne operations are usually carried out with little notice, whilst the form of the operation or the number of aircraft available@ make predetermined procedures and staff tables of limited use. Great emphasis has to be placed on flexibility in thinking, planning and preparation. To instill this flexibility Brigade exercises over the last two years have all been based on scenarios sufficiently different to require completely different plans. The early involvement of medical staff in Brigade planning $>$ facilitates medical flexibility. Flexibility does, however, pose difficulties for individuals; the younger soldier trying to learn "the system" is confused by the constant" change, whilst older personnel, used to more rigid ways $N$ of doing things, tend to equate change with inefficiency or indecision. 
The second problem area is related to the human factors referred to earlier. The impact of lack of sleep, the long journey, the personal loads, the unknown terrain and heat in addition to the other stresses of battle cannot be overstated. Enforced rest prior to deployment (possibly aided by drugs such as Temazapam), the maintenance of a high level of fitness and the ability to experience many of these stresses on exercise should reduce their impact on a real operation to some extent, but cannot abolish them.

The main problems, however, usually start with the parachute delivery of the first Battalion Group. Rarely does the delivery go according to plan. Personnel and freight may be dropped wide or not arrive at all. In the invasion of Europe in 1944 one parachute field ambulance (224) found that two thirds of its personnel, most of its freight, and none of its re-supply actually arrived $^{3}$. Narrative reports held by 23 PFA on its participation in the invasion of the South of France in 1944 tell of parts of the unit being dropped so far off target that it took enquiries at local farmhouses to determine their exact location. This was followed by $a d$ hoc groups fighting their way over a period of 30 hours to join up with the main part of the unit, treating casualties they encountered on the way. The problems can be alleviated. Medical personnel are carried on a number of aircraft to ensure some arrive. They are usually seated in different positions in the aircraft so that there should be an even distribution of medical personnel on the $\mathrm{DZ}$, making rapid first aid available to those injured on the drop, although this delays rendezvous procedure. Parachute selection and training will have hopefully resulted in officers and men who have the initiative, knowledge and determination to act independently and correctly in the event that things have gone wrong. Equipment is distributed to ensure that the loss of personnel does not mean the loss of a capability. For instance anaesthetic vaporisers and drugs are shared between the anaesthetists and operating theatre technicians whilst all personnel are taught that they may have to act "one or two" up (and equally on occasions may have to act one or two down as well!).

Once the first PCT has landed, there will be difficult choices if the $D Z$ is separate from the Battalion objective. Clearing the DZ can take 12 hours at night, and longer if major casualties are sustained. In the parachute assault into Greece in 1945 the unit narrative report records 97 casualties with two fatalities. The OC of the PCT (usually the unit second in command) will have to decide how to split his resources between the $\mathrm{DZ}$ and the support of the Battalion in its attack on its objective. No firm plan can be made in advance as the decision will depend on the number of casualties on the $\mathrm{DZ}$, the number of his personnel and amount of his freight that have arrived, and casualties sustained due to enemy action. A particular problem is to decide when to start operating, as once operating has started the PCT should remain static for a reasonable period, although both at Arnhem and in the invasion of the South of France, field ambulances had to move with immediate post-operative cases ${ }^{4}$. Other factors that have to be considered are the lack of casualty evacuation transport and the location of the future Brigade DS. Luckily the original objective is usually close to or the same as the DZ. This, of course, results in other problems as the PCT can find itself in the thick of the fighting. In Normandy 224 Parachute Field Ambulance reports that during the first four days after their parachute assault they were surrounded by the enemy who were rarely more that 500 yards from the DS. During that period the DS admitted 822 casualties and performed 112 major operations. To continue to work in such conditions requires a certain resilience amongst personnel!

The second PCT, with the second Battalion to arrive, should not have these problems, especially if it airlands, when it should easily be able to join up with the first PCT to form a DS. If it arrives by parachute, however, and, by accident or design, ends up deployed separately from the first - on exercises this has happened by accident a number of times - there is then the problem of joining them up. Usually they will both have post-operative surgical cases making a simple "close and move" impossible. In any case, with only two vehicles there are other problems which will delay the amalgamation of the two PCT's. The Brigade will by now be undertaking more ambitious operations requiring casualt 8 evacuation over increasing distances and the collecting sections will require to be deployed. They are initially delivered with their trailer, and left. If required, the battalion will redeploy them or they will wait until a fiel ambulance landrover is available. There are also the various "unit" command and administrative tasks which require vehicles. The amalgamation of the two PCT's has to be co-ordinated with all of these other tasks, and is usually phased over many hours, commencing with the move of the surgical teams, followed by the transfer of casualties, and finishes with the move of the remaining equipment and personnel.

Once the Field Ambulance is complete in theatre there are some problems associated with the small size and light scales of the unit and the Brigade and its method of operating. The small establishment causes two problems. With only three collecting sections it could be difficult to provide reinforcements to all the Brigade's major units and hold a reserve. The small size of the Clearing Troop seriously affects the standard of post-operative care that could be given if rearward evacuation were delayed for long. The problem can be alleviated to some extent by using elements of $1 \mathrm{~A}$ Evac $\mathrm{S}$ or 22 Field Hospital to reinforce the ward, but, even then, casualties are only held for the minimum period. The light scales call for flexibility and there is no place for restrictive practices. No sub-unit or individual (including the Commanding Officer) owns his vehicles. Indeed this applies to all the Brigade vehicles, and, subject to the Laws of Armed Conflict, Field Ambulance 
vehicles can be tasked by Brigade. The Battalion Regimental Aid Posts are usually deployed well forward, often on foot with the Battalion Tactical HQ, or independently as a result of being left behind when treating casualties. This forward Regimental Aid Post deployment results in the most seriously injured casualties getting prompt and expert attention, but it poses difficulties for the field ambulance which has to go forward to collect them. This is partially eased by allocating to the Battalions which are in action a Collecting Section and some landrovers, fitted to carry stretchers, for use not only between the Regimental Aid Post and the DS, but also (unlike elsewhere in the British Army) for evacuation directly from the point of woundings. The vehicle crews get to know the area, and, as the less serious casualties need not be off-loaded at the Regimental Aid Post or the attached section, it speeds up evacuation. As the landrovers fitted for stretcher are fitted with radios on the field ambulance net, the one possible disadvantage of this system, a loss of flexibility in the Brigade as a whole, is avoided as the vehicles can be, and are, retasked when required elsewhere.

Luckily many of these evacuation problems are avoided by the use of helicopters. All commanders in 5 AB Bde seem to be agreed that a major use of both light and support helicopters will be casualty evacuation. This, however, poses other problems as the control of a helicopter landing site, with (even on exercise) up to 6 helicopters queuing either to deliver or collect casualties, is difficult. A radio on the air net so far seems only to emphasise the problem, and there is the danger that casualties could be accidently transferred out of a helicopter delivering them to the DS directly to one evacuating from the DS without any treatment in between!

Four further areas need to be mentioned - the place of forward surgery, the splitting of the unit, the handling of refugees and documentation.

The first, forward surgery, is controversial. Most, if not all, of the world's airborne medical services have integral surgery whose presence is expected by the fighting troops and which is claimed to be useful by the surgeons and doctors of the airborne forces. The need for its presence prior to the opening of rearward evacuation is undisputed. It is the policy after lines of evacuation are opened, and especially when third line hospital facilities have been deployed, that is controversial. Current $5 \mathrm{AB}$ Bde policy is to retain at least two surgical teams forward, but only to operate on those casualties who would not otherwise survive a journey rearwards. Post-operative cases are evacuated by helicopter within 18 hours of operation. This policy is adopted for a number of reasons. Firstly, it is believed that, for those with severe internal bleeding, forward surgery saves lives that would otherwise be lost; secondly, without the personnel of the Surgical Troop, 23 PFA has not the manpower to form a DS which could carry out the conventional tasks of a DS; and, thirdly lines of evacuation can easily be blocked. As an illustration of the last reason, it is noted that, when weather precluded helicopter flying prior to the attack on Port Stanley in the closing stage of the Falklande Island campaign, the two Parachute Surgical Teams were moved forward from Ajax Bay to provide forward: surgery. Also experience in Vietnam, Israel and thess Falklands shows that even post-operative laparotomyo cases can withstand early evacuation by helicopter ${ }^{5}$ 믐 Early evacuation may be necessary for two reasons $\frac{\bar{s}}{\frac{1}{2}}$ tactical (to maintain the mobility of the unit) and practical (because of the limited manpower available fow ward care). It is accepted that in general war thes shortage of surgical teams may preclude forward deployment, but it is an option which arguably should $\leftarrow$ be developed for use in the event that evacuation does become seriously delayed in some part of the battlefield.

Splitting the DS is avoided wherever possible because it is a small unit. However, when the unit has to cover ani airhead as well as operations elsewhere it will split. Ir this event it is planned that a greater element of 1 A Evaci $S$ or an advance element of 22 Field Hospital would be deployed to enhance ward care. The success of the two small surgical elements deployed forward in the? Falkland Islands suggests that splitting, while difficiojt, $\vec{c}$ certainly is a viable option.

In recent years it has been found that one of the mos likely tasks to involve medical units is the treatment and evacuation of civilians from a country affected by war 100 natural disaster. Examples of this include the evacuation of British civilians from Cyprus during the Turkisho invasion and from Aden in 1985, or assisting Jamaican authorities during floods in 1986. (The firsto and last of these events involved Airborne Forces, albeito in a conventional as opposed to airborne role.) Civilians@ would include the young, the old and the chronically ill.F्大 In fact the administration of refugees poses mores problems than does their medical care, and a major unit? Headquarters Company in $5 \mathrm{AB}$ Bde is tasked with, and? trains in, their administration, and that unit's Regimental Aid Post is responsible for the refugee's primary medical care. Any who are seriously ill are evacuated to the field ambulance in the normal way. Additional medical supplies, for paediatric and obstetriow care for instance, are held in medical depots and would be collected prior to deployment. It would be sensible to take some female nurses as well. In addition to specialist. medical material for civilians, tropical supplements areo available for the Field Ambulance and the Regimental Aid Posts.

The final problem is that of documentation. Whereas $>$ in general war the names of casualties may not be․ㅡ. required urgently in the UK, this is not true for out of area operations. In order to ensure that the names of casualties reach the UK as quickly as possible - ando certainly before they are reported in the press - the Brigade Field Records Office is colocated with the DS 
and the DS uses the same listing procedures of seriously and very seriously ill that are employed in peace.

To conclude the article, reference must once again be made to the individuals. The success or otherwise of an airborne operation depends on the calibre of the personnel at all levels. Any officer, NCO or even private soldier may suddenly find himself in the position of a Commander, and the success or failure of an operation will depend on the individual's ability to weld the team together, and to make, and act on, a rapid appreciation of the situation. Unfortunately the qualities required are more common in their absence than in their presence and at the time of writing the success rate for volunteers for Parachute Selection in 23 PFA is under $25 \%$ for medical and dental officers and under $30 \%$ for soldiers on their first attempt. The rate is even lower amongst the other rank specialist trades (Operating Theatre Technician, Clerk, Environmental Health Technician and Nurse). As a result 23 PFA is now retraining Combat Medical Technicians who have passed Parachute Selection against deficiencies in the other trades, except in nursing where a deficiency still remains. It has been suggested that for some trades and for some specialist officers the standards should be relaxed, but such is the quality of the soldiers that only officers who are as fit as the rank and file and have recognised leadership qualities are likely to be effective. In any case history shows that on operations no individual will be exempt from the rigours, hardships and responsibilities associated with Airborne Operations and the success of such operations, more than on any others, depends on the quality of the individual officer and soldier. It is because all Airborne Forces select their personnel (including medical personnel) carefully, that almost all airborne operations have been successful and their accompanying medical support has always been considered to have been of a high standard.

\section{REFERENCES}

1. Statement on Defence Estimates 1984, Vol 1, Cmnd 9227-1.

2. The Falkland Islands Campaign: The Lessons, Cmnd 8758.

3. Young A D. The Parachute Field Ambulance. JR Army Med Corps 1947; LXXXIX: 235-249.

4. ColE H. On Wings of Healing. Blackwood \& Sons, Edinburgh \& London 1963 pp 61 and 113

5. Dolev E D. Early Evacuation from the Battlefield After Laparotomy: Experience in Vietnam, Israel and the Falklands. In press.

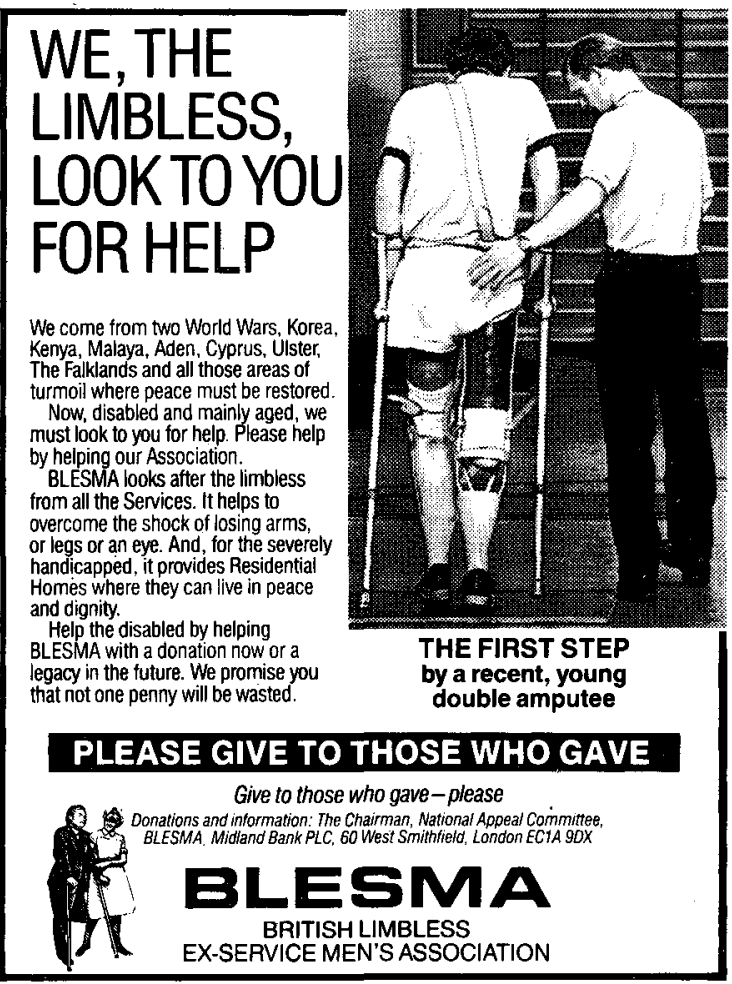

